\title{
The Accidental Salesperson: Can Inexperienced Sales Professionals Get Lucky Without Working Smart or Hard? An Abstract
}

\author{
Joël Le Bon
}

\begin{abstract}
Inexperienced sales professionals face high probability of failure, especially at an early career stage (Cron and Slocum 1986). One of the reasons for failure in sales pertains to the difficulty for salespeople to control their market environment. In fact and from an attribution theory perspective, the sales environment is unstable and difficult to control (Teas and McElroy 1986), thus also binding sales success to good or bad luck (Dixon et al. 2001, 2003).

The theory of attribution helps understand and explain how salespeople react to failure and bounce back (Dixon et al. 2001; Dixon and Schertzer 2005; Sujan 1986; Teas and McElroy 1986). The theory also is of particular importance in education to analyze how learners interpret performance and redirect effort (Weiner 1979). The attribution theory is concerned with individuals' search for causes of their failures and successes; a natural tendency to redirect effort on appropriate behavior to improve performance (Heider 1958; Kelley 1967). Three central causal dimensions have been discerned, namely stability, locus, and controllability (Weiner 1979). Stability refers to the extent to which the cause of failure or success is perceived as being stable (native ability or task difficulty), or unstable (effort or luck). Locus deals with one's perception of the location of the cause, namely internal (native ability or effort), or external (task difficulty or luck). Finally, controllability relates to individuals' perception of their ability to affect their achievement by controlling the cause (effort), or not (native ability, task difficulty, and luck).

Analyzing the impact of luck on sales performance is a legitimate question which should help understand how inexperienced sales professionals face uncertainty and leverage a working smart or working hard strategy in their market environment (Sujan 1986; Sujan et al. 1994). Findings show that working smart and working hard influence sales performance differently when lucky happenstances are at stake.
\end{abstract}

References Available Upon Request

J. Le Bon $(\bowtie)$

University of Houston, Houston, USA

e-mail: jlebon@bauer.uh.edu 